\title{
Effects of KW-5092, a Novel Gastroprokinetic Agent, on the Delayed Colonic Propulsion in Rats
}

\author{
Kotaro Takasaki, Nobuyuki Kishibayashi, Akio Ishii and Akira Karasawa \\ Department of Pharmacology, Pharmaceutical Research Laboratories, Kyowa Hakko Kogyo Co., Ltd., \\ 1188 Shimotogari, Nagaizumi-cho, Sunto-gun, Shizuoka 411, Japan \\ Received December 21, 1993 Accepted March 4, 1994
}

\begin{abstract}
The effects of KW-5092, \{1-[2-[[[5-(piperidinomethyl)-2-furanyl]methyl]amino]ethyl]-2-imidazolidinylidene $\}$ propanedinitrile fumarate, on the loperamide- or clonidine-induced delayed propulsion were determined in rats and compared with those of other gastroprokinetic agents. Administration of loperamide $(0.3 \mathrm{mg} / \mathrm{kg}$, s.c.) or clonidine $(0.01 \mathrm{mg} / \mathrm{kg}$, s.c.) induced delay of the evacuation time of the teflon ball, which had been inserted into the distal colon. The delayed evacuation was improved dosedependently by KW-5092 at 3 to $10 \mathrm{mg} / \mathrm{kg}$ (p.o.) or higher. Neostigmine at 0.3 to $3 \mathrm{mg} / \mathrm{kg}$ (p.o.) and T-1815 at 1 to $100 \mathrm{mg} / \mathrm{kg}$ (p.o.) also improved the delayed ball evacuation. These results suggest that KW-5092 stimulates the delayed colonic propulsion.
\end{abstract}

Keywords: KW-5092, Colon (rat), Constipation

KW-5092, \{1-[2-[[[5-(piperidinomethyl)-2-furanyl]methyl] aminol ethyl] - 2 -imidazolidinylidene $\}$ propanedinitrile fumarate, is a ranitidine derivative devoid of histamine $\mathrm{H}_{2}$-receptor blocking activity. $\mathrm{KW}-5092$ possesses acetylcholine esterase inhibitory activity and exhibits potentiating action on electrically evoked contractions of the isolated guinea pig ileum (1). Furthermore, KW-5092 enhances motility of the gastric antrum and colon in anesthetized rabbits (1), suggesting that KW-5092 stimulates motility of the alimentary tract in general. Colonic transport activity can be estimated by measuring the time required to excrete a small ball inserted into the colon of mice or rats $(2-5)$. A lag in the evacuation of the ball is known to be caused by the opioid agonist loperamide (5) and by the $\alpha_{2}$ adrenergic receptor agonist clonidine (4). In the present study, we examined whether administration of KW-5092 can restore the delayed colonic propulsion induced by loperamide or clonidine in rats by determining the evacuation time of a teflon ball.

Male Sprague-Dawley rats (Japan SLC Inc., Hamamatsu), weighing 150-220 g, were used for the experiment. All animals received humane care in compliance with the "Guiding Principles for the Care and Use of Laboratory Animals" formulated by the Bioethical Committee of the Pharmaceutical Research Laboratories, Kyowa Hakko Kogyo Co., Ltd. Prior to the experiment, the animals were fasted $18-22 \mathrm{hr}$ but were access to drinking water ad libitum. The drugs used were KW-5092, HSR803 ( $N$-[4-[2-(dimethylamino)ethoxy]benzyl]-3,4-dimethoxybenzamide hydrochloride) (6), AS-4370 (4-amino-5chloro-2-ethoxy- $N$-((4-(4-fluorobenzyl)-2-morpholinyl) methyl)benzamide citrate) (7), T-1815 (( \pm$)$-1-[(3,4-dimethoxy benzyl)oxymethyl]-1-(2-thienyl)- $N, N$-dimethyl- $n$-propylamine 2-(4-hydroxybenzoyl)benzoate) (5), ranitidine, cisapride and neostigmine. KW-5092, AS-4370, HSR$803, T-1815$ and ranitidine were synthesized in our laboratories. Cisapride was provided by Janssen-Kyowa (Tokyo). Neostigmine, loperamide and clonidine were purchased from Sigma Chemical Co., Ltd. (St. Louis, MO, USA). KW-5092, HSR-803, neostigmine and ranitidine were dissolved in distilled water. Cisapride and AS4370 were suspended in $0.3 \%$ sodium carboxymethyl cellulose (Daiichi Pure Chemicals, Tokyo), Loperamide and clonidine were dissolved in saline.

The effects on the delayed colonic propulsion were determined with a modification of the reported method (5). The animals were orally administered with each drug at a volume of $5 \mathrm{ml} / \mathrm{kg}$; and $30 \mathrm{~min}$ later, they were given an s.c. injection of $0.3 \mathrm{mg} / \mathrm{kg}$ of loperamide or $0.01 \mathrm{mg} / \mathrm{kg}$ of clonidine. These dosages were enough to delay the ball evacuation, the evacuation time being about 6 times longer than that in the control animals in the preliminary examination. One hour after treatment with the test compound, a teflon ball, $3.17 \mathrm{~mm}$ in diameter, was inserted 
into the distal colon at $3 \mathrm{~cm}$ from the anus under light ether anesthesia. The time required to evacuate the ball was measured until $2 \mathrm{hr}$ later and used as an index of colonic propulsive activity. Data were presented as means \pm S.E. Significance of the difference was tested with the Wilcoxon rank sum test, the Williams-Wilcoxon test or Steel's test. Differences at values of $\mathrm{P}<0.05$ were considered to be statistically significant.
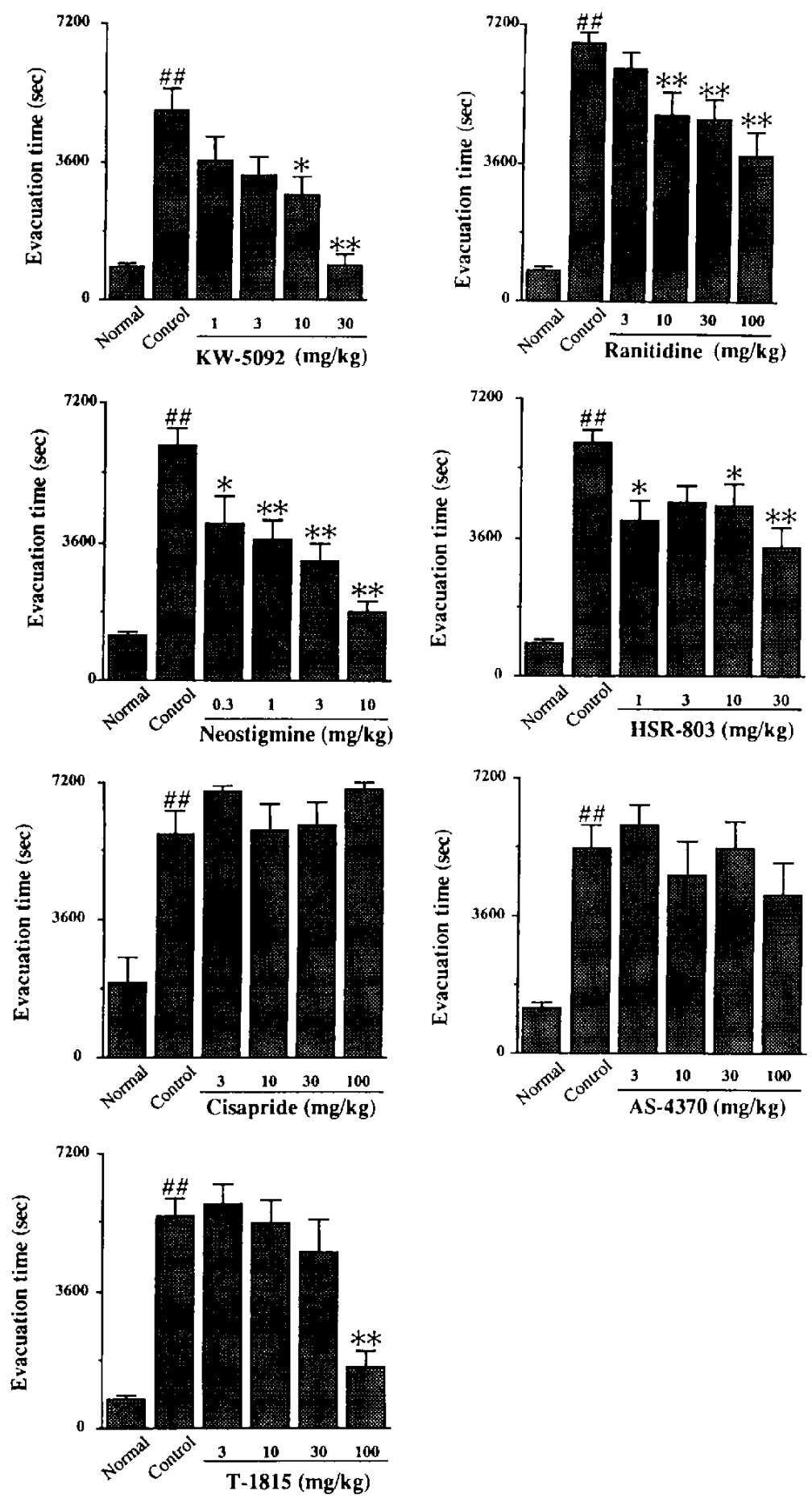

Fig. 1. Effects of KW-5092, neostigmine, cisapride, T-1815, ranitidine, HSR-803 and AS-4370 on the evacuation time in loperamide-treated rats. The test drugs were orally administered $1 \mathrm{hr}$ before and loperamide $(0.3 \mathrm{mg} / \mathrm{kg})$ was subcutaneously given 30 min before the ball insertion. ${ }^{\# \#:}: \mathbf{P}<0.01$, significant difference from the normal group. ${ }^{*} * *: P<0.05, P<0.01$, significant difference from the control group, respectively. Each column indicates the mean \pm S.E.M. of 10-15 animals. 
The effects on the loperamide-induced delay of colonic propulsion are shown in Fig. 1. The vehicle of each drug had no effect on the evacuation time of the ball (data not shown). Loperamide at a dose of $0.3 \mathrm{mg} / \mathrm{kg}$, s.c. significantly delayed the ball evacuation (3.0-8.6 times of the normal). KW-5092 $(1-30 \mathrm{mg} / \mathrm{kg})$, neostigmine $(0.3-10 \mathrm{mg} / \mathrm{kg})$ and $\mathrm{T}-1815(3-100 \mathrm{mg} / \mathrm{kg})$ improved the loperamide-induced delay of colonic propulsion in
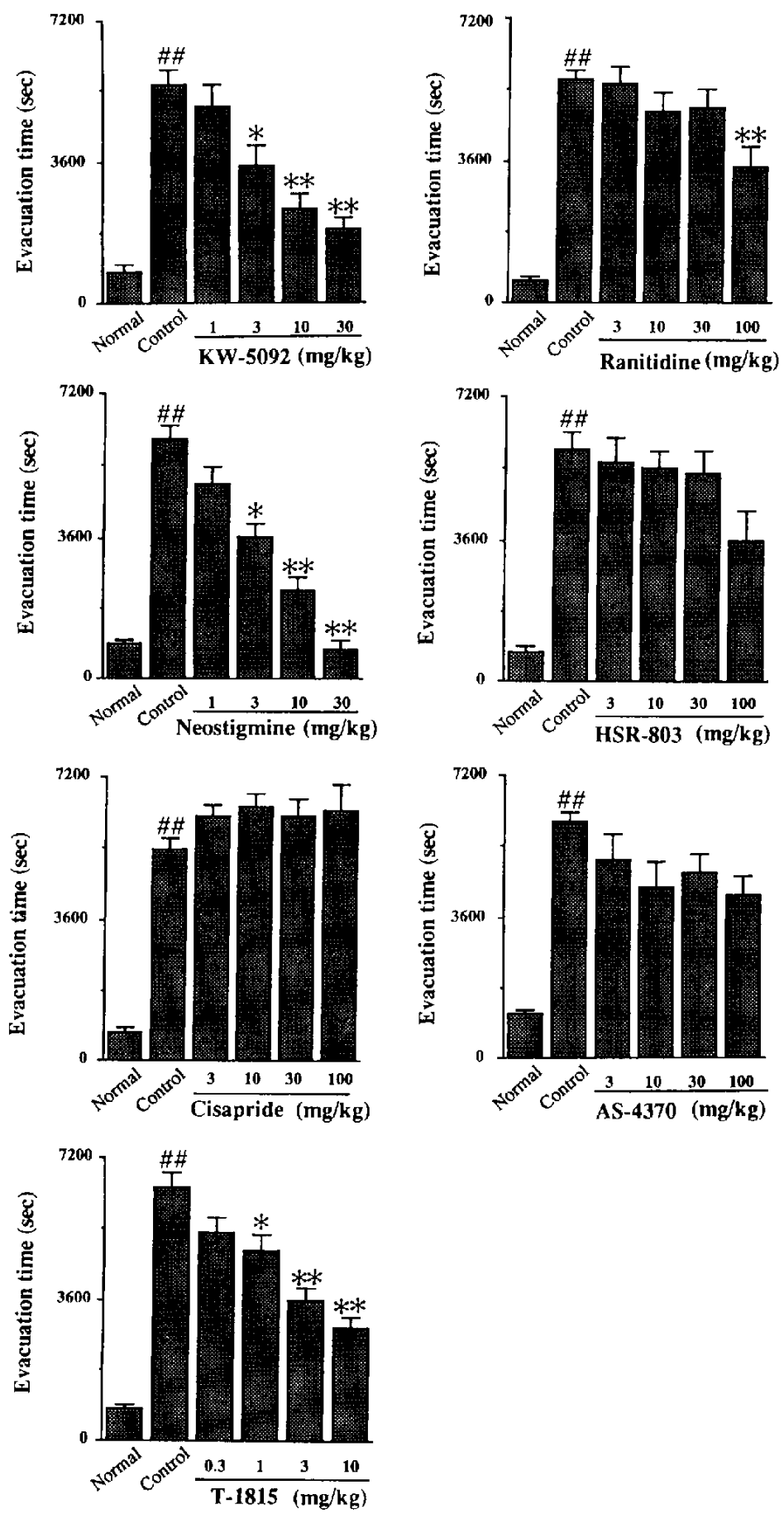

Fig. 2. Effects of KW-5092, neostigmine, cisapride, T-1815, ranitidine, HSR-803 and AS-4370 on the evacuation time in clonidine-treated rats. The test drugs were orally administered $1 \mathrm{hr}$ before and clonidine $(0.01 \mathrm{mg} / \mathrm{kg})$ was subcutaneously given 30 min before the ball insertion. ${ }^{\#}: \mathrm{P}<0.01$, significant difference from the normal group. ${ }^{* * *}: \mathrm{P}<0.05, \mathrm{P}<0.01$, significant difference from the control group, respectively. Each column indicates the mean \pm S.E.M. of $10-15$ animals. 
dose-dependent manners. The $\mathrm{ID}_{50}$ (the dose producing $50 \%$ inhibition) values of KW-5092, neostigmine and T1815 were $3.6 \mathrm{mg} / \mathrm{kg}, 0.8 \mathrm{mg} / \mathrm{kg}$ and $51.4 \mathrm{mg} / \mathrm{kg}$, respectively. HSR $-803(1-30 \mathrm{mg} / \mathrm{kg})$ also shortened the delay of ball evacuation; however, it showed no dose-dependency. Neither cisapride nor AS-4370 produced any improvement of the colonic propulsion at up to $100 \mathrm{mg} / \mathrm{kg}$.

The effects on the clonidine-induced delay of colonic propulsion are shown in Fig. 2. Clonidine at a dose of $0.01 \mathrm{mg} / \mathrm{kg}$ also significantly delayed the ball evacuation. $\mathrm{KW}-5092(1-30 \mathrm{mg} / \mathrm{kg})$, neostigmine $(1-30 \mathrm{mg} / \mathrm{kg})$ and $\mathrm{T}-1815(0.3-10 \mathrm{mg} / \mathrm{kg})$ decreased the clonidine-induced delay of ball evacuation, as was the case with the loperamide-induced delay of colonic propulsion. The $\mathrm{ID}_{50}$ values of KW-5092, neostigmine and $\mathrm{T}-1815$ were 5.5 $\mathrm{mg} / \mathrm{kg}, 3.5 \mathrm{mg} / \mathrm{kg}$ and $3.7 \mathrm{mg} / \mathrm{kg}$, respectively. Ranitidine $(3-100 \mathrm{mg} / \mathrm{kg})$ showed an improvement of colonic propulsion; however, a significant improvement of the colonic propulsion was observed only at a high dose of 100 $\mathrm{mg} / \mathrm{kg}$.

HSR-803, which is known to release acetylcholine from cholinergic nerve terminals (6), had a weak effect as compared with KW-5092 in both the constipation models. Although ranitidine showed improving activity in both the constipation models in dose-dependent manners, it did not attain the $50 \%$ effect even at $100 \mathrm{mg} / \mathrm{kg}$. Cisapride and AS-4370 did not cause any significant improvement in the present constipation models. This effect is in accordance with the previous observation that AS$4370 \mathrm{had}$ no effect on the distal alimentary tract (7).

It has been reported that T-1815, a trimebutine derivertive, showed improving effects on loperamide- (minimum effective dose $=1.0 \mathrm{mg} / \mathrm{kg}, \mathrm{p} .0$.) and clonidine- (minimum effective dose $=0.3 \mathrm{mg} / \mathrm{kg}, \mathrm{p} . \mathrm{o}$.) induced constipation in mice (5). In the present study, T-1815 showed improving effects in both the constipation models; however, the minimum effective doses for the loperamide- and the clonidine-induced constipation were $100 \mathrm{mg} / \mathrm{kg}$ (p.o.) and $1 \mathrm{mg} / \mathrm{kg}$ (p.o.), respectively. These discrepancy may be due to differences in the experimental conditions such as the animal species examined and the doses of the agents inducing constipation.

It is known that clonidine inhibits the release of acetylcholine from cholinergic nerve terminals via stimulation of the $\alpha_{2}$-adrenergic receptor (4). Since clonidine shows suppressive action on the small intestine both in vivo (5) and in vitro (8), clonidine-induced delay of colonic propulsion can be regarded as a model of atonic constipation. On the other hand, loperamide shows a tonic effect on the guinea pig colon, resulting in an inhibition of peristalsis (9). Consequently, loperamide-induced delay of colonic propulsion is considered to be a model of spastic constipation. In the present study, we demonstrated that KW-5092 clearly and dose-dependently improves the loperamide- and clonidine-induced delayed colonic propulsion in the rat and that the $\mathrm{ID}_{50}$ values for $\mathrm{KW}$ 5092 in the loperamide- and clonidine-induced constipation were similar $(3.6 \mathrm{mg} / \mathrm{kg}$ and $5.5 \mathrm{mg} / \mathrm{kg}$, respectively). The present results suggest that KW-5092 may be useful for the treatment of patients with constipation of both the atonic and the spastic types.

Neostigmine, which is known as an acetylcholine esterase inhibiting agent, showed an improving action 4.5fold stronger than that of KW-5092 in the loperamide-induced constipation. On the other hand, it showed similar potency to KW-5092 in the clonidine-induced constipation. The difference in the activities of neostigmine and KW-5092 between the clonidine- and loperamide-induced models may be due to the difference in the mode of actions of these agents. Neostigmine is an established inhibitor of acetylcholine esterase. In contrast, KW-5092 has not only the acetylcholine esterase inhibitory action (1) but also the ability to induce acetylcholine release from the cholinergic nerve ending (10). Thus, it is likely that the acetylcholine releasing effect of KW-5092 is more involved in the amelioration of the loperamide-induced constipation, where the acetylcholine release is intact, than in that of the clonidine-induced constipation, where the acetylcholine release is inhibited.

In summary, the present study demonstrates that KW5092 improves the delayed propulsion indused by loperamide or clonidine in rats. As KW-5092 has the stimulatory effect on cholinergic neurons, it is suggested that $\mathrm{KW}$ 5092 is useful for the treatment of diseases accompanied with the dysfunction of cholinergic neurons.

\section{REFERENCES}

1 Sasho $\mathrm{S}$, Obase $\mathrm{H}$, Ichikawa $\mathrm{S}$, Kitazawa $\mathrm{T}$, Nonaka $\mathrm{H}$, Yoshizaki R, Ishii A and Shuto K: Synthesis of 2-imidazolidinylidenepropanedinitrile derivatives as stimulators of gastrointestinal motility. 1. J Med Chem 36, 572-579 (1993)

2 Schottek W: The "glass ball test" - an informing method for testing the influence of pharmaca on the peristalsis of the colon of rats. Arzneimittelforschung 17, 649-650 (1967)

3 Jacoby HI and Lopez I: A method for the evaluation of colonic propulsive motility in the mouse after icv administered compounds. Dig Dis Sci 29, 551 (1984)

4 Pendleton RG, Bendesky R and Cook PG: Effects of alpha 2adrenoceptor agonists upon colonic propulsion. Drug Dev Res 9, 241-247 (1986)

5 Yamada K and Onoda Y: Comparison of the effects of T-1815, yohimbine and naloxone on mouse colonic propulsion. $J$ Smooth Muscle Res 29, 47-53 (1993)

6 Iwanaga Y, Miyashita N, Morikawa K, Mizumoto A, Kondo Y and Ito $Z$ : A novel water-soluble dopamine-2 antagonist with anticholinesterase activity in gastrointestinal motor activity. Gastroenterology 99, 401-408 (1990)

7 Yoshida K, Ito T, Karasawa T and Ito Z: AS-4370, a new gas- 
trokinetic agent, enhances upper gastrointestinal motor activity in conscious dogs. J Pharmacol Exp Ther 257, 781 - 787 (1991)

8 Doherty NS and Hancoch AA: Role of alpha 2 adrenergic receptors in the control of diarrhea and intestinal motility. $J$ Pharmacol Exp Ther 225, 269-274 (1983)

9 Sohji Y, Kawashima K and Shimizu M: Pharmacological studies of loperamide, an antidiarreal agent. II. Effects on peristal- sis of the small intestine and colon in guinea pigs. Folia Pharmacol Jpn 74, 155- 163 (1978) (Abstr in English)

10 Kishibayashi N, Ishii A and Karasawa A: Enhancement by KW5092, a novel gastroprokinetic agent, of the release of acetylcholine from enteric neurons in the guinea pig ileum. Jpn J Pharmacol 64, 289-295 (1994) 